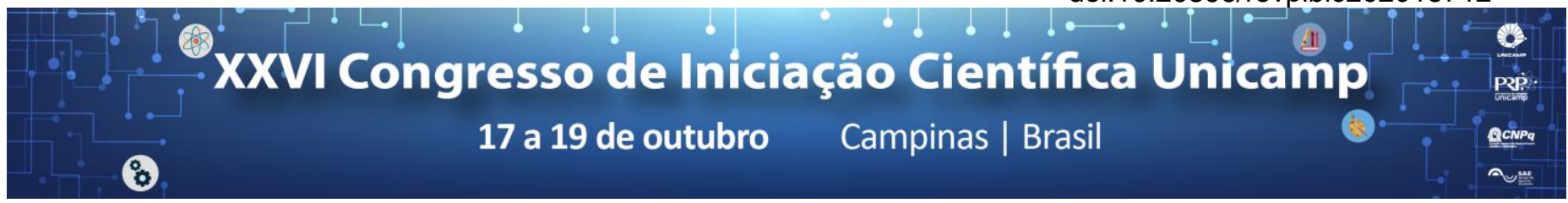

\title{
Remoção de matéria orgânica do soro de queijo em reator anaeróbio de leito fixo ordenado (ABFSB)
}

\section{Júlia Gomes Moretti, Gustavo Mockaitis, Nicolas Duarte Cano.}

\section{Resumo}

O presente projeto analisou a remoção de matéria orgânica em um biorreator anaeróbio de leito fixo ordenado (ABFSB) proposto por Mockaitis et al. (2014). Foram realizadas análises de DQO, alcalinidade, ácidos voláteis, sólidos totais e dissolvidos como medidas da eficiência e estabilidade do sistema. O afluente do ABFSB foi soro de queijo em pó reconstituido suplementado com o meio nutriente de Del Nery (1987). Após 77 dias de operação o reator alcançou uma eficiência máxima de $57,5 \%$, e após 30 dias de partida, podemos verificar uma estabilidade de operação.

\section{Palavras-chave:}

Reator anaeróbio, produção de biocombustível, soro de leite.

\section{Introdução}

O soro de leite é um resíduo altamente poluente que vem sendo descartado nos rios sem nenhum tipo de tratamento, acarretando um grande problema ao ambiente, já que em sua composição possuí grande quantidade de matéria orgânica. Seu potencial poluente (DQO 60 a $80 \mathrm{~g} \mathrm{~L}^{-1}$ ), ultrapassa em cem vezes 0 potencial das águas residuais domésticas (Bezerra et. al., 2007). Para cada quilograma de queijo produzido, pode ser produzido até 9 litros de soro de queijo, sendo o agente principal da poluição emitida no processo de produção de queijo. O objetivo do trabalho desenvolvido foi analisar a remoção de matéria orgânica (em termos de DQO) em um ABSFB, utilizando soro de leite como substrato, e consequentemente reduzindo 0 seu potencial poluente.

\section{Resultados e Discussão}

O ABFSB foi operado continuamente por 125 dias em condições mesofílicas $\left(30^{\circ} \mathrm{C}\right)$ e operando com um tempo de detenção hidráulica (TDH) de 8 horas. O ABFSB foi alimentado por um afluente cuja concentração média foi de 475,3 mg O2 L-1, com um pH médio de 6,5 considerada uma faixa ideal para a metanogânese (Corneli et al., 2016). O inóculo utilizado foi o lodo de reator UASB tratando resíduo de abatedouro de aves (Pereiras/SP). Substrato foi o soro de queijo em pó reconstituído com a solução de nutrientes descrita por Del Nery (1987).

A figura 1 mostra a remoção da matéria orgânica no ABFSB, correspondendo a uma eficiência média de $46,1 \%$. A média do valor dos sólidos totais na entrada do ABFSB foi de $0,0006 \mathrm{mg} \mathrm{L}^{-1}$ e na saída foi de $0,0005 \mathrm{mg}$ $\mathrm{L}^{-1}$. A concentração de ácidos voláteis totais no afluente do biorreator foi de $371,9 \mathrm{~g} \mathrm{~L}^{-1}$, em comparação com $411,7 \mathrm{~g} \mathrm{~L}^{-1}$ encontrada no efluente.

A alcalinidade no afluente foi de $208,2 \mathrm{~g} \mathrm{~L}^{-1}$ e no efluente foi de $228,9 \mathrm{~g} \mathrm{~L}^{-1}$.

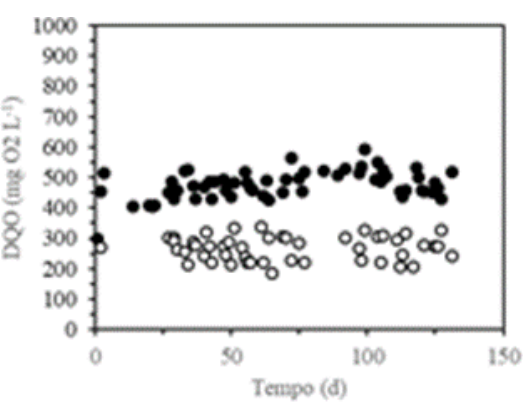

Figura 1. Remoção da Matéria Orgânica realizada pelo reator (ABSFB), na qual: $\bullet$ - afluente e $\bigcirc$ - efluente.

\section{Conclusões}

O ABFSB é uma tecnologia de processamento anaeróbio que demonstra potencial na aplicação do tratamento do soro de queijo. Neste trabalho exploratório, o ABFSB removeu $46 \%$ da matéria orgânica presente na água residuária. Conforme Chernicharo (1997), reatores contínuos eficientes removem $68 \%$ de matéria orgânica, concluindo que o reator $A B F S B$ não é considerado eficiente nas condições experimentais que foram realizadas esse projeto. Desta forma, são necessários mais estudos para.

\section{Agradecimentos}

A todos os alunos e ao meu orientador do Grupo Interdisciplinar de Biotecnologia na Agricultura e no Meio Ambiente (GBMA) que de forma direta me auxiliaram na realização de todo 0 projeto.

Corneli, E., Dragoni, F., Adessi, A., Philippis, R. De, Bonari, E., \& Ragaglini, G. (2016). Energy conversion of biomass crops and agroindustrial residues by combined biohydrogen/biomethane system and anaerobic digestion. Bioresource Technology, 211, 509-518.

Borges, A.C.P., Silva, M.S., Alves, C.T., Torres, E.A., 2016. Renewable energy: a contextualization of the biomass as power supply. REDE: Revista Eletrônica do PRODEMA 10, 23-36. doi:10.22411/rede2016.1002.02

Chernicharo, C. A. L.. Reatores Anaeróbios. 2 edição. Belo Horizonte: Departamento de Engenharia Sanitária e Ambiental - UFMG, 1997.

Camiloti, P.R., Mockaitis, G., Domingues Rodrigues, J.A., Rissato Zamariolli Damianovic, M.H., Foresti, E., Zaiat, M., 2014. Innovative anaerobic bioreactor with fixed-structured bed (ABFSB) for simultaneous sulfate reduction and organic matter removal. Journal of Chemical Technology and Biotechnology 89, 1044-1050. doi:10.1002/jctb.4199 